\title{
Crystal growth kinetics of two-step growth process in liquid fluidized-bed crystallizers
}

\author{
Clifford Y. Tai* \\ Department of Chemical Engineering, National Taiwan University, Taipei 106, Taiwan, ROC \\ Received 17 March 1999; accepted 27 May 1999 \\ Communicated by M. Schieber
}

\begin{abstract}
The fluidized-bed crystallizers have long been used in the chemical industry and recently for water treatment as the so-called pellet reactors. This report summarizes the experimental results regarding hydrodynamics and crystal growth rates in laboratory-scale fluidized-bed crystallizers. The two-step crystal growth model rather than the over-all model is adopted to explain the observed kinetic behaviors. In using the two-step growth model, the disadvantage is the uncertainty of the surface-reaction order. A reliable method is suggested to explore the surface-reaction order using a lean fluidized-bed crystallizer. The crystal growth process of sparingly soluble salts, which have been studied recently for a few systems, seems more complex than that of soluble salts. Then, a comparison of crystal growth kinetics of soluble salts is made between the dense and lean fluidized-bed crystallizers. As a conclusion, the two-step growth model is suitable for the estimation of crystal growth rates in the design of a liquid fluidized-bed crystallizer. (C) 1999 Elsevier Science B.V. All rights reserved.
\end{abstract}

Keywords: Crystal growth kinetics; Liquid fluidized bed; Two-step growth model; Sparingly soluble salts; Soluble salts

\section{Introduction}

Fluidized beds have been adopted as separators for many operations in the chemical industry, especially for the crystallization operation. The most efficient modern industrial crystallizers are of suspended-type bed, in which the crystals are grown in a liquid fluidized zone. A supersaturated solution in the metastable region enters the bottom of the bed and the supersaturation is partially released when the solution passes through the growth zone. For example, the Oslo-Krystal Crystallizers belong to the fluidized-bed type, in which the gentle action

*Fax: + 886-2-362-3040. between crystals or between the crystal and the vessel wall minimizes secondary nucleation and allows crystals to grow to a larger size [1]. Therefore, fluidized-bed crystallizers are suitable for producing many organic and inorganic chemicals. Recently, a fluidized bed has been used in water treatment. A pellet reactor, which is a reactive fluidized-bed growth-type crystallizer, has been developed for water softening of drinking water [2] fluoride and phosphate removal $[3,4]$, and for heavy metal recovery from waste streams [5]. The water feed and the chemicals required to cause deposition are fed to the reactor containing suspended seeds of several hundred micrometers. The undesired species react to form insoluble salts, such 


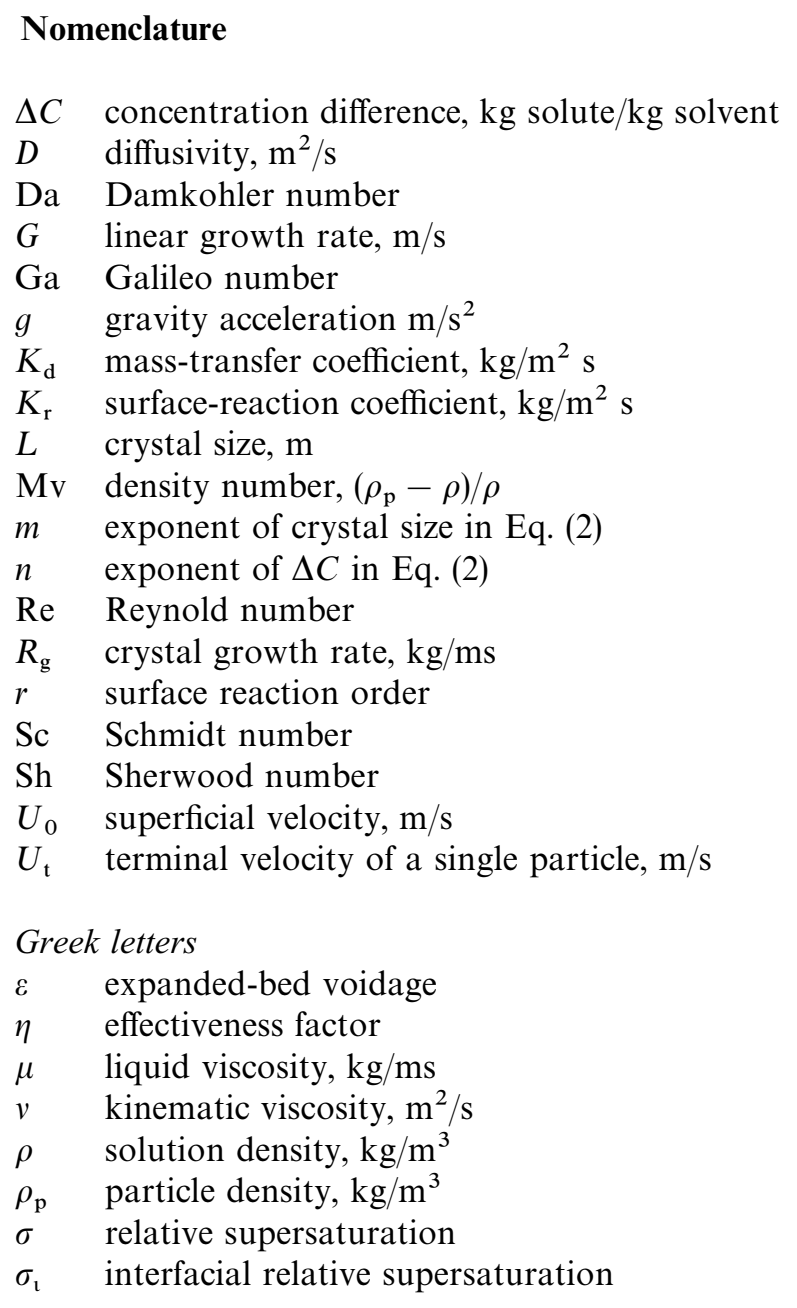

as calcium ion to form calcite $\left(\mathrm{CaCO}_{3}\right)$ in water softening, and then grown on the seeds, which are later removed from the reactor after exceeding a certain size. When compared with the conventional precipitation process, in which tiny precipitates form in the bulk solution due to primary nucleation, the major advantages of this newly developed clean technology are the avoidance of sludge formation, the possibility of material recovery and the reduction of solid waste.

One of the most important parameters needed in the design of a fluidized bed is the upflowing liquid velocity necessary to keep the crystals in suspen- sion. Depending on the superficial velocity applied, two types of beds are classified, i.e., the dense bed and the lean bed. The former is operated at a superficial velocity lower than the particle terminal velocity to give the bed a clear solution-suspension boundary. In the later, the superficial velocity is approaching the particle terminal velocity and the particles move freely in the bed with no solutionsuspension boundary. There are two disadvantages associated with the lean bed, i.e., low seed loading due to a high-bed voidage and carry-over of particles due to a fluctuation of solution velocity. Although dense beds are most commonly used in the 
chemical industry, the hydrodynamics in the bed is more complicated. The crystals, being present in a large quantity, are subjected to hindered settling and further complication arises if the crystals have irregular shape and size distribution. Besides, the bed voidage changes with the up-flowing liquid velocity, resulting in different liquid flow patterns. On the other hand, the flow pattern is simple in a lean bed, which resembles a plug flow with the relative velocity between the particle and liquid being almost the same as the superficial velocity. Thus, a lean bed is usually used in the laboratory to study the crystal growth mechanism.

To design a fluidized-bed crystallizers, the crystal growth rates should be available besides knowing the hydraulics of a fluidized bed. The crystal growth is a complex process, which includes many steps such as diffusion, adsorption, dehydration, integration, and others. Thus, there are many factors that affect the crystal growth rate. The factors are summarized by Mullin [1] and Sohnel and Garside [6], including growth rate dispersion, crystal size, solution velocity, admixtures, magnetic field, temperature, and $\mathrm{pH}$. The influence of most of the factors to each of the growth step is still unknown, that a general expression of crystal growth rate is difficult to establish, especially for the sparingly soluble systems. This report summarized the studies related to the crystal growth in a lab-scale fluidized-bed crystallizer, either a lean or a dense one. Then an experimental procedure in search of crystal growth rate, which is used for the design of a fluidized-bed crystallizer, is suggested.

\section{Design and operation of fluidized beds}

A typical lab-scale fluidized-bed crystallizer, which provides reliable crystal growth data quickly, is designed by Mullin et al. [7] as shown in Fig. 1. The apparatus includes the main crystallization Section A where crystals grows, the calming Section B to avoid carry-over of crystals, the variable speed pump $\mathrm{E}$ to deliver different flow rates of solution, the temperature control system (heat exchanger $J$, resistance thermometer $D$, heating tapes $G$, and a temperature controller) to maintain the desired temperature in the crystallization section,

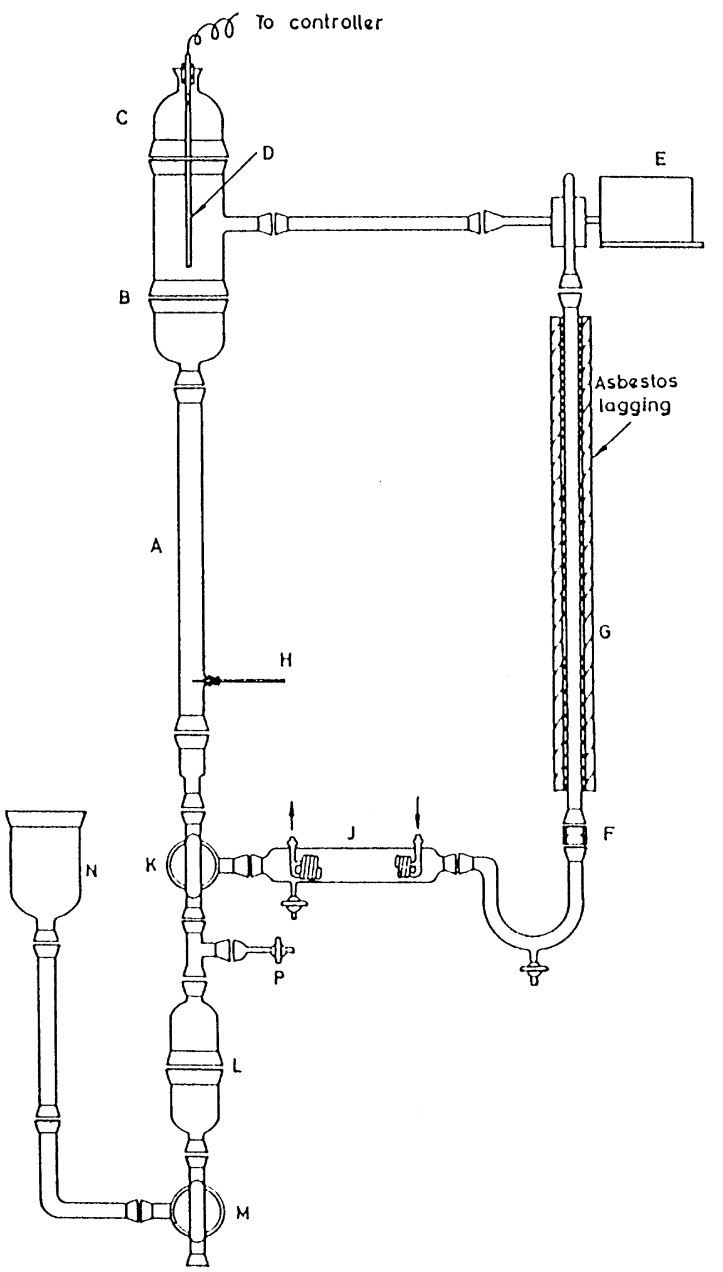

Fig. 1. A typical laboratory-scale fluidized-bed crystallizer [7].

and the salt catching assembly (three-way cock $K$, salt box $L$ and solution reservoir $N$ ). The important features of this design are adopted later by the researchers in this field, perhaps with a slight modification by inserting a distributor in front of the crystallization section for an even flow of solution.

The major physical operating variables of a fluidized bed are the particle diameter, the superficial velocity and the fixed-bed height. These parameters, together with the temperature and the physical properties of the particle and the solution, completely determine the other properties of the system, such as bed voidage, expanded-bed height, specific surface area, head loss, and energy 


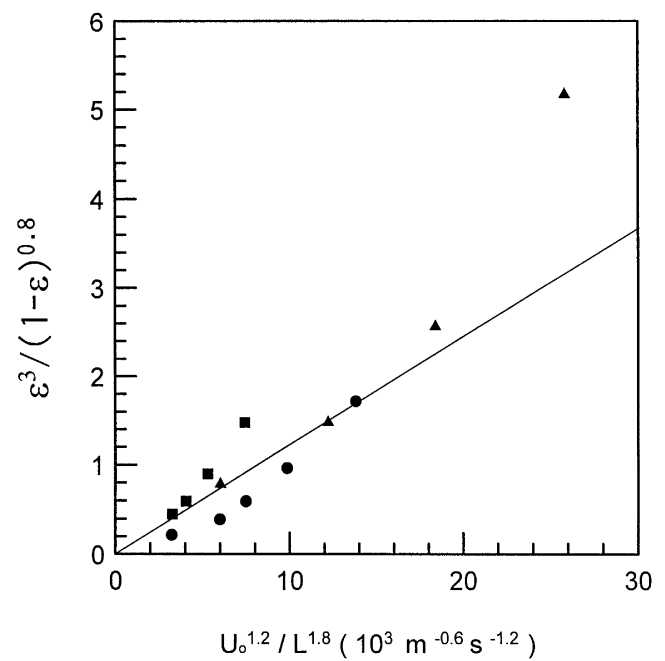

Fig. 2. A plot of Eq. (2) for calcite crystals suspended in a fluidized bed.

dissipation. Van Dijk and Wilms [5] derived the bed porosity or voidage for the Reynolds number in a range between 5 and 100 .

$\frac{\varepsilon^{3}}{(1-\varepsilon)^{0.8}}=130 \frac{v^{0.8}}{g} \frac{\rho}{\rho_{\mathrm{p}}-\rho} \frac{U_{0}^{1.2}}{L^{1.8}}$, where $\varepsilon$ is the bed voidage, $v$ the kinematic viscosity, $\rho$ the solution density, $\rho_{\mathrm{p}}$ the particle density, $U_{0}$ the superficial velocity and $L$ the particle size. By varying the superficial velocity between the minimum fluidization velocity and the particle terminal velocity, they suggest a suitable range of particle size, $0.3 \mathrm{~mm}<L<1.5 \mathrm{~mm}$, for the operation of a fluidized bed and conclude that the particles $\leqslant 0.3 \mathrm{~mm}$ are too small because of excessive expansion and the particles $\geqslant 1.5 \mathrm{~mm}$ are too large because of small surface area for a batch crystallizer.

Tai and $\mathrm{Wu}[8]$ studied the velocity-voidage relation for the rhombohedron calcite fluidized in a laboratory-scale crystallizer. The agreement between the experimental data and Eq. (1) is fairly good except for a datum point of high voidage $(\varepsilon=0.91)$ as shown in Fig. 2 . The experimental data are tabulated in Table 1.

\section{Over-all crystal growth rate model}

Before early 1980s, most of the crystal growth rate data measured in a dense fluidized bed were presented by an over-all rate model, which is expressed in terms of the crystal size and the

Table 1

Superficial velocity-bed voidage relationship for calcite crystals suspended in a fluidized bed

\begin{tabular}{|c|c|c|c|c|}
\hline $\begin{array}{l}\text { Particle size } \\
L(\mu \mathrm{m})\end{array}$ & $\begin{array}{l}\text { Superficial velocity } \\
U_{0}(\mathrm{~m} / \mathrm{s})\end{array}$ & $\begin{array}{l}\text { Bed voidage } \\
\varepsilon(-)\end{array}$ & $\begin{array}{l}\varepsilon^{3} /(1-\varepsilon)^{0.8} \\
(-)\end{array}$ & $\begin{array}{l}U_{0}^{1.2} / L^{1.8} \\
\left(10^{3} \mathrm{~m}^{-0.6} \mathrm{~s}^{-1.2}\right)\end{array}$ \\
\hline 460 & $\begin{array}{l}0.0139 \\
0.0233 \\
0.0353 \\
0.0469\end{array}$ & $\begin{array}{l}0.68 \\
0.77 \\
0.84 \\
0.91\end{array}$ & $\begin{array}{l}0.782 \\
1.479 \\
2.567 \\
5.172\end{array}$ & $\begin{array}{l}6.01 \\
11.2 \\
18.4 \\
25.8\end{array}$ \\
\hline 651 & $\begin{array}{l}0.0139 \\
0.0233 \\
0.0281 \\
0.0353 \\
0.0469\end{array}$ & $\begin{array}{l}0.50 \\
0.58 \\
0.64 \\
0.71 \\
0.79\end{array}$ & $\begin{array}{l}0.217 \\
0.390 \\
0.593 \\
0.963 \\
1.718\end{array}$ & $\begin{array}{c}3.21 \\
5.98 \\
7.48 \\
9.84 \\
13.8\end{array}$ \\
\hline 921 & $\begin{array}{l}0.0236 \\
0.0283 \\
0.0353 \\
0.0469\end{array}$ & $\begin{array}{l}0.60 \\
0.64 \\
0.70 \\
0.77\end{array}$ & $\begin{array}{l}0.449 \\
0.593 \\
0.898 \\
1.479\end{array}$ & $\begin{array}{l}3.25 \\
4.04 \\
5.27 \\
7.41\end{array}$ \\
\hline
\end{tabular}


driving force

$G=K L^{m}(\Delta C)^{n}$

where $G$ is the linear crystal growth rate, $L$ the crystal size, $\Delta C$ the concentration difference between the supersaturated and saturated solutions, $m$ and $n$ the constants.

The values of $m$ and $n$ have been determined for several systems, including potassium nitrate [9], sodium chloride [10], potassium alum [11], potassium sulfate $[12,13]$, nickel sulfate $[14]$ and citric acid [15].

The over-all growth rate is simple to use for design purpose. However, the applicability of growth rate is limited to the small range of operating variables investigated. It is not reliable to make estimation outside the operating conditions nor in the scale-up of crystallizer.

\section{Two-step crystal growth model}

Several mechanisms regarding crystal growth have been proposed in Ref. [1]. Among them the two-step growth model is considered most useful from the chemical engineering point of view. The model takes into account the mass-transfer and surface-reaction resistance in series and neglects all other resistance in a crystal growth process. At steady-state conditions, the two steps can be represented by the following equations:

$R_{\mathrm{g}}=K_{\mathrm{d}}\left(\sigma-\sigma_{\mathrm{l}}\right) \quad$ mass transport

and

$R_{\mathrm{g}}=K_{\mathrm{r}} \sigma_{\mathrm{t}}^{r} \quad$ surface reaction.

Due to the uncertainty of $r$ and unknown $\sigma_{\imath}$, the model was not adopted at the time when it was proposed. Recently, attempts have been made to determine the individual rate constants, $K_{\mathrm{d}}$ and $K_{\mathrm{r}}$, and the surface reaction order $r$.

Tavare and Chivate [16] and Langer and Offermann [17] measured the crystal growth and dissolution rates of potassium sulfate and potassium alum, respectively, in a dense fluidized-bed crystallizer. They assumed that the mass-transfer coefficient of crystal dissolution is identical to that of crystal growth and then determined the kinetics of the surface-reaction step; i.e., the mass-transfer coefficient of crystal dissolution is substituted into Eq. (3) to calculate $\sigma_{\mathrm{t}}$ and then $K_{\mathrm{r}}$ and $r$ were determined according to Eq. (4).

Assuming that $r$ has a "standardized" value of 2 for several systems, including copper sulfate, potassium alum, magnesium sulfate and sodium thiosulfate, Karpinski and his co-workers [18-22] determined the individual rate constants from the following equation, which is derived by combining Eqs. (3) and (4):

$\sigma R_{\mathrm{g}}^{-1 / 2}=K_{\mathrm{d}}^{-1} R_{\mathrm{g}}^{1 / 2}+K_{\mathrm{r}}^{-1 / 2}$

The growth kinetics of mass transfer and surface reaction were revealed, for example, the masstransfer coefficient of crystal growth is the same as that of crystal growth; the surface-reaction coefficient is a function of crystal size and exhibits a maximum when cation admixture is present; the activation energy of diffusion step changes at 318 $\mathrm{K}$ for potassium alum crystal, indicating a change in diffusion mechanism above $318 \mathrm{~K}$.

The use of $r=2$ should be cautious; however, it may be applied to some systems. For example, the surface-reaction order of potassium alum is proven to be 2 over a wide range of supersaturation in a single crystal experiment [23]. Thus, assuming $r=2$, Tai and his co-workers [24,25] analyzed the crystal growth and dissolution rate data of potassium alum obtained in a lean fluidized-bed crystallizer, which is different from the dense bed used by Karpinski and his co-workers [18] and reached some unexpected results. Suppose the lean fluidized bed is operated near the crystal terminal velocity of a uniform crystal size, the solution velocity is related to the crystal size by the following form:

$U_{0}=\left[\frac{4}{225} \frac{\left(\varrho_{\mathrm{p}}-\varrho\right)^{2} g^{2}}{\varrho \mu}\right]^{1 / 3} L$.

When Eq. (6) is substituted into the Froessling equation, which is $\mathrm{Sh}=0.6 \mathrm{Re}^{1 / 2} \mathrm{Sc}^{1 / 3}$, the resultant equation has the following form:

$\mathrm{Sh}=0.306 \mathrm{Ga}^{1 / 3} \mathrm{Mv}^{1 / 3} \mathrm{Sc}^{1 / 3}$.

The mass-transfer coefficient of crystal dissolution obtained in the experiment is identical to that of 


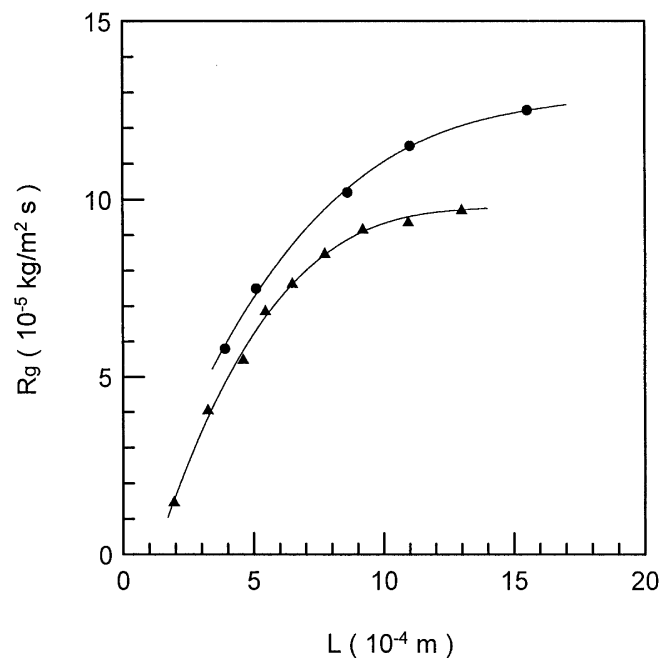

Fig. 3. Plots of growth rate versus crystal size for potassium alum and potassium sulfate crystals: $(\mathbf{O}) \mathrm{K}_{2} \mathrm{SO}_{4}$ [12]; (A) Kalum [25].

crystal growth and follows Eq. (7), which shows that the mass-transfer coefficient is independent of solution velocity and crystal size, and it is a function of system properties only because the crystal size in Sherwood number and in Galileo number is canceled out. Thus, for the size-dependent growth rate of potassium alum shown in Fig. 3, the surface reaction is responsible for the size-dependent growth and the crystal growth rates tend to be constant for large crystals. Note that a crystal growth rate curve of $\mathrm{K}_{2} \mathrm{SO}_{4}$ is included in the figure, which is reported by Mullin and Gaska [12] and has a similar shape of the K-alum system. Once $r, K_{\mathrm{d}}$ and $K_{\mathrm{r}}$ are known, the controlling step of crystal growth process can be judged from the effectiveness factor, which is defined by Eq. (8) for a second-order surface reaction [26]:

$\eta=(1-\eta \mathrm{Da})^{2}$,

where $\mathrm{Da}=\sigma K_{\mathrm{r}} / K_{\mathrm{d}}$.

When Da is large, growth is diffusion controlled. Conversely, when Da is small, growth is surfacereaction controlled. Thus in Fig. 3, the crystal growth process of potassium alum is surface-reaction controlled for crystal size below $4 \times 10^{-4} \mathrm{~m}$. As crystal size increases, the mass-transfer resistance becomes significant. After the crystal size exceeds
$2 \times 10^{-3} \mathrm{~m}$, both coefficients are constant, giving a constant growth rate. There is no dominating step for larger sizes of potassium alum crystal as judged from the effectiveness factor.

\section{Determination of surface-reaction order}

One of the disadvantages of using the two-step crystal growth model is the unknown of the surface-reaction order. In some reports, the value of $r$ is simply assumed [18,27] or the mass-transfer coefficient of crystal growth is replaced by that of crystal dissolution and then to determine the surface-reaction order $[16,17]$. These two methods are not reliable. Although the mass-transfer process of crystal growth is the reverse process of crystal dissolution, the corners of the crystal become rounded quickly in a dissolution experiment, causing an error in the determination of $K_{\mathrm{d}}$ for small crystals [24].

Tai et al. [25] suggested a method to determine the surface-reaction order using a lean fluidized bed. When a fluidized-bed crystallizer is operated near the crystal terminal velocity, the mass-transfer coefficient is a constant for a given system and can be estimated from Eq. (7). Note that the crystal size in Eq. (7) is canceled out, thus $K_{d}$ is a function of system properties only, including diffusivity, densities, and viscosity. Once $K_{\mathrm{d}}$ is known, $\sigma_{\mathrm{t}}$ can be calculated from Eq. (3) using the $R_{\mathrm{g}}-\sigma$ data. Then, $r$ is determined from Eq. (4) by plotting $\ln R_{\mathrm{g}}$ versus $\ln \sigma_{\imath}$. The surface-reaction orders estimated from the available data of potassium alum from various sources are listed in Table 2, and they are close to 2. One disadvantage of using Eq. (7) is that the diffusivity data are available for limited systems, and the determination of diffusivity needs skillful techniques [28].

A comparison of surface reaction order, which has been supported by experimental evidence, in different types of crystallizer is presented by Tai [29]. The values of $r$ obtained in a single crystal growth cell and fluidized-bed crystallizer are rather consistent, either 1 or 2 , which are the values often predicted by the spiral growth [30]. In a stirredtank crystallizer, the value of $r$ is usually higher than 2 , including potassium sulfate, calcium 
Table 2

Surface reaction order of potassium alum, estimated from Eq. (4)

\begin{tabular}{rlllll}
\hline$L \times 10^{5}(\mathrm{~m})$ & $T\left({ }^{\circ} \mathrm{C}\right)$ & Range of $\sigma$ & $r$ & Corr. coef. & Reference \\
\hline 530 & 32.0 & $0.017-0.087$ & 2.03 & 0.998 & {$[11]$} \\
990 & 32.0 & $0.006-0.075$ & 2.13 & 0.993 & {$[11]$} \\
1730 & 28.5 & $0.026-0.128$ & 2.06 & 0.997 & {$[18]$} \\
907 & 28.5 & $0.026-0.128$ & 1.82 & 0.999 & {$[18]$} \\
1095 & 23.5 & $0.059-0.147$ & 2.01 & 0.993 & {$[24]$} \\
194 & 23.5 & $0.043-0.142$ & 2.10 & 0.998 & {$[25]$} \\
\hline
\end{tabular}

carbonate, and succinic acid, however; $r$ is close to 2 in the fluidized bed for the two former systems. The high order of surface-reaction kinetics can be explained by the NAN growth model, which is the only growth model that predicts $r>2$ [30]. Another thing worth mentioning is that the impurity may affect the surface-reaction order and different types of impurity yield different effects. For example, the surface-reaction order of magnesium sulfate is 1 for pure system and the additive of dye does not change the order [23]. However, the order changes from 1 to 2 when inorganic species, $\mathrm{Cr}^{3+}$ or $\mathrm{Fe}^{3+}$, is added to the solution $[19,31]$.

\section{Crystal growth of sparingly soluble salts}

The study of crystal growth of sparingly soluble salts in a fluidized bed is scarce because of its limited application. Besides, the growth experiment of a sparingly soluble salt is more difficult than that of a soluble salt. In the former, the $\mathrm{pH}$ should be well controlled in order to prevent nucleation [32]. Recently, the pellet reactor, which is a reactive fluidized-bed crystallizer, has been used to remove calcium ions, fluoride ions, phosphate ions, heavy metal ions and others from water streams. For design purpose, the crystal growth rates of sparingly soluble salts, such as carbonates, sulfides, and others are required. So far, the systems of calcium sulfate (gypsum), calcium fluoride (fluorspar) and calcium carbonate (calcite) are reported. However, the sparingly soluble systems will be widely studied because of the urgent need of clean technologies.

For the design of pellet reactors to remove calcium ion, which is a major species of hard water, and fluoride ion, which is a pollutant in the waste stream from a semi-conductor plant, Tai and his co-workers studied the crystal growth of calcium fluoride and calcium carbonate in a batch fluidized bed, using a pH-stat apparatus as shown in Fig. 4 [3,8,34]. The important feature of the apparatusis the maintenance of constant $\mathrm{pH}$ controlled by an autotitrator. The metastable regions of calcite and fluorspar were found and the growth experiments were successfully conducted in this region without significant nucleation. Factors that affect the crystal growth rate in a dense fluidized bed, include supersaturation, crystal size, superficial velocity, $\mathrm{pH}$, ionic strength, and type of seed. The crystal growth process of a sparingly soluble salt seems more complicated than a soluble salt. The electrical double layer around a crystal is speculated to play a role in the crystal growth process of a sparingly soluble salt because the crystal growth rate is lower at high-ionic strength, which reduces the thickness of electrical double layer. At the present time a crystal growth model to include all the significant factors is difficult to establish. However, under similar environment of $\mathrm{pH}$, ionic strength, and species ratio, the growth rate data in a lean fluidized bed show that the mass-transfer coefficient is independent of crystal size and superficial velocity and the surfacereaction coefficient is a function of crystal size, all consistent with the results of soluble systems.

\section{Comparison of growth kinetics in dense and lean beds}

The hydrodynamics in a dense bed seems quite different from that in a lean bed and the 


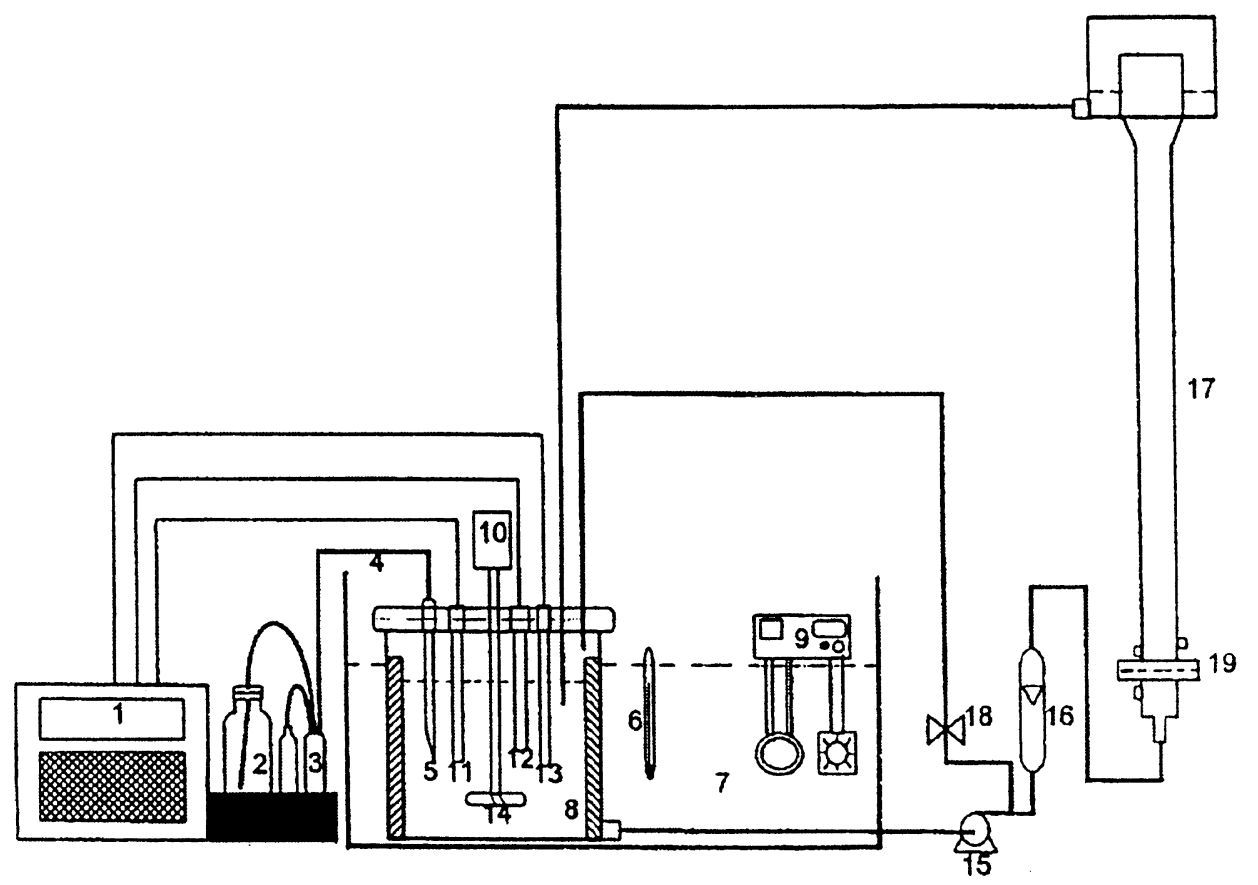

Fig. 4. A pH-stat crystallization system. (1) pH and temperature indicator, (2) reagent bottle, (3) pumping system of reagent, (4) reagent delivering line, (5) burette, (6) thermometer, (7) water bath, (8) storage tank, (9) temperature controller, (10) motor, (11) glass electrode, (12) reference electrode, (13) thermo-compensator, (14) axial-flow impeller, (15) magnetic pump, (16) flowmeter, (17) fluidized bed reactor, (18) ball valve, (19) distributor.

mass-transfer process is related to the hydrodynamics. Therefore, it is interesting to compare the crystal growth kinetics of the two beds.

Mullin and his co-workers [12,13] measured the crystal growth rates of potassium sulfate in a dense $(\varepsilon=80-85 \%)$ and lean $(\varepsilon>0.95)$ fluidized bed. The results show good agreement for these two types of bed. However, a correlation to predict the masstransfer coefficient is not established.

The crystal growth rates of potassium alum in a dense bed and a lean bed are measured by Budz et al. [18] and Tai et al. [24], respectively. The crystal growth rates were calculated by Eq. (3) using the mass-transfer coefficient in the respective report. The mass-transfer coefficient of dense bed has been corrected to $296.5 \mathrm{~K}$ using the activation energy reported by Budz et al. [20]. Again, a good agreement exists between the two sets of data as shown in Fig. 5.

The good agreement for the crystal growth rates between the dense and lean fluidized bed is under- stood through the following argument. The constant crystal growth rate means that the surface-reaction and mass-transfer coefficients are the same in the two types of fluidized bed. The surface reaction is a surface phenomenon and should be independent of hydrodynamics encountered in the two-types of fluidized bed. As far as the masstransfer coefficient is concerned, it is usually considered as a function of crystal size and solution velocity. However, according to Eq. (7), the masstransfer coefficient in a lean bed is independent of crystal size and superficial velocity, which is almost the same as terminal velocity or relative velocity, and is a function of system properties only. In other words, the mass-transfer coefficient is a constant for a given system. As the superficial velocity is reduced, the bed voidage and thus the cross-sectional area for the passage of solution become smaller than that of a lean bed. When the solution passes through the crystal bed, the relative velocity, which is the slip velocity between solution and crystal, 


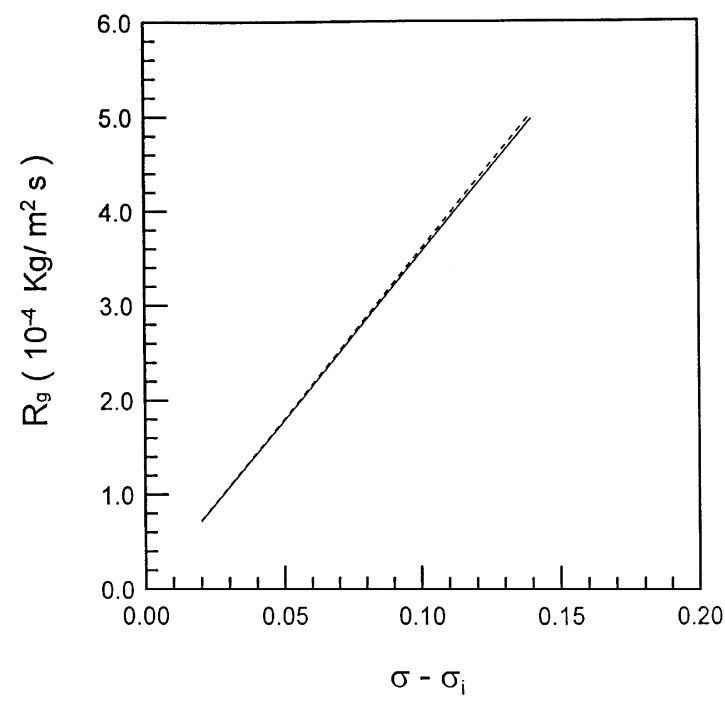

Fig. 5. Comparison of potassium alum growth rates at $296.5 \mathrm{~K}$ for dense and lean bed: (-) dense bed [18]; (- - -) lean bed [24].

becomes higher than the reduced superficial velocity. It is possible that the relative velocity, which is the velocity that determines the mass-transfer coefficient, in a dense bed is almost equal to the terminal velocity of crystals regardless of bed voidage. As a result, the mass-transfer coefficients in a lean bed and dense bed are identical.

The constant mass-transfer coefficient is also supported by the evidences in the crystal dissolution experiments. Tournie et al. [33] analyzed extensive dissolution data reported in the literature for both lean and dense fluidized beds, and they concluded that the mass-transfer coefficient was practically independent of liquid solution and particle size.

\section{Conclusions}

After analyzing a large amount of crystal growth data, the crystal growth process of soluble salts seems not too complex in a liquid fluidized bed. The two-step crystal growth model is good enough to explain the observed crystal growth kinetics in a lean or dense bed. A reliable method has been proposed to determine the parameters of the twostep growth model, using a lean fluidized bed. For sparingly soluble salts, the growth process is more complicated, but the two-step model can be applied under a similar environment of $\mathrm{pH}$, ionic strength, and species ratio. Nevertheless, the variation of these operating conditions is quite small in a largescale operation. Besides, the hydrodynamic behaviors between large- and laboratory-scale fluidizedbed crystallizers are not much different as compared with other types of equipment. Therefore, the estimation of crystal growth rates for design purpose is more confident after tremendous efforts have put forth in this field.

\section{Acknowledgements}

The author gratefully acknowledges the financial support of the National Science Council of the Republic of China in the research area of crystal growth through the years.

\section{References}

[1] J.W. Mullin, Crystallization, 3rd edition, ButterworthHeinemann, Oxford, 1993, Chapter 8.

[2] P. Dirken, E. Barrs, A. Graveland, C.F. Woensdregt, in: A. Mersmann (Ed.), Industrial Crystallization 90, GarmischPartenkirchen, Germany, 1990, p. 95.

[3] C.Y. Tai, T.M. Tsao, P.-C. Chen, M.-S. Lee, Industrial Crystallization 96, Toulouse, France, 1996, p. 123.

[4] M.M. Seckler, O.S.L. Bruinsma, G.M. van Rosmalen, J.C. van Dijk, F. Delgorge, Industrial Crystallization 90, Garmisch-Partenkirchen, Germany, 1990, p. 143.

[5] J.C. van Dijk, D.A. Wilms, J. Water SRT-Aqua 40 (1991) 263.

[6] O. Sohnel, J. Garside, Precipitation-Basic Principles and Industrial Applications, Butterworths-Heinemann, London, 1992, Chapter 3.

[7] J.W. Mullin, J. Garside, C. Gaska, Chem. Ind. 41 (1966) 1704.

[8] C.Y. Tai, J.-F. Wu, J. Chin. Inst. Chem. Eng. 29 (1998) 9.

[9] S.H. Bransom, A.G.C. Palmer, Br. Chem. Eng. 9 (1964) 672.

[10] R.C. Bennett, Chem. Eng. Prog. 58 (1962) 76.

[11] J.W. Mullin, J. Garside, Trans. Inst. Chem. Eng. 45 (1967) T291.

[12] J.W. Mullin, C. Gaska, Can. J. Chem. Eng. 47 (1969) 483.

[13] J. Garside, C. Gaska, J.W. Mullin, J. Crystal Growth 13/14 (1972) 510.

[14] V.R. Phillips, N. Epstein, A.I.Ch.E. J. 20 (1974) 678. 
[15] C. Laguerie, H. Angelino, Growth rate of citric acid monohydrate crystals in a fluidized bed, Industrial Crystallization 75, Plenum Press, New York, 1976, p. 135.

[16] N.S. Tavare, M.R. Chivate, Trans. Inst. Chem. Eng. 57 (1979) 35.

[17] H. Langer, H. Offermann, Industrial Crystallization 84, Elsevier, Amsterdam, 1984, p. 297.

[18] J. Budz, P.H. Karpinski, Z. Nuruc, A.I.Ch.E. J. 30 (1984) 710.

[19] P.H. Karpinski, J. Budz, M.A. Larson, Industrial Crystallization 84, Elsevier, Amsterdam, 1984, p. 85.

[20] J. Budz, P.H. Karpinski, Z. Nuruc, A.I.Ch.E. J. 31 (1985) 259.

[21] P.H. Karpinski, Chem. Eng. Sci. 35 (1980) 2321.

[22] P.H. Karpinski, Chem. Eng. Sci. 40 (1985) 641.

[23] C.Y. Tai, C.-H. Lin, J. Crystal Growth 82 (1987) 377.

[24] C.Y. Tai, C.-Y. Chen, J.-F. Wu, Chem. Eng. Commun. 56 (1987) 329.
[25] C.Y. Tai, J.-F. Wu, C.-Y. Shih, J. Chem. Eng. (Japan) 23 (1990) 562.

[26] J. Garside, Chem. Eng. Sci. 26 (1971) 1425.

[27] T. Ishi, Chem. Eng. Sci. 28 (1973) 1121.

[28] A.W. Nienow, Bri. Chem. Eng. 10 (1965) 827.

[29] C.Y. Tai, J. Chem. Eng. (Japan) 30 (1997) 373.

[30] J. Nyvlt, O. Sohnel, M. Matuchova, M. Broul, The Kinetics of Industrial Crystallization, Elsevier, Amsterdam, 1985, Chapter 4.

[31] C.Y. Tai, C.-S. Cheng, Y.-C. Huang, J. Crystal Growth 123 (1992) 236.

[32] C.Y. Tai, P.-C. Chen, S.-M. Shih, A.I.Ch.E. J. 39 (1993) 1472.

[33] P. Tournie, C. Lagurie, J.P. Couderc, Chem. Eng. Sci. 34 (1979) 1247.

[34] C.Y. Tai, W.-C. Chien, C.-Y. Chen, A.I.Ch.E. J. (1999), in press. 